\title{
¿EFICACIA HORIZONTAL DE LOS DERECHOS FUNDAMENTALES? EL PROBLEMA DEL ESTÁNDAR DE LA PRUEBA ILÍCITA EN EL DERECHO CHILENO*
}

\author{
Francisco Jara Bustos** \\ Universidad de Chile, Chile \\ franciscojara1@gmail.com
}

RESUMEN: El presente trabajo aborda el progresivo establecimiento de reglas de exclusión probatoria en procesos civiles como un problema. La existencia de un estándar idéntico al penal en materia civil y de familia, y -más exigente- en materia laboral, inevitablemente genera una crisis de coherencia en nuestro sistema jurídico, y nos obliga a preguntarnos por la eficacia horizontal de los derechos fundamentales.

Palabras clave: prueba ilícita, derecho a la prueba, regla de exclusión, eficacia horizontal, reforma procesal civil.

\section{HORIZONTAL EFFECT IN THE FUNDAMENTAL RIGHTS? THE ILLEGAL EVIDENCE STANDARD PROBLEM IN THE CHILEAN LAW}

\begin{abstract}
The paper analyzes the progressive establishment of the exclusionary rule in non criminal procedures, as a problematic decision. The existence of an identical standard in criminal, civil and family justice, and one -even greater- in the new labor justice, inevitably generates a crisis of coherence in our legal system, and forces us to ask ourselves about the horizontal effect of human rights.
\end{abstract}

Keywords: illegal evidence, right of proof, exclusionary rule, horizontal effect, civil procedure reform.

A la memoria de Félix Bustos Bustos

Trabajo recibido el 30 de agosto y aprobado el 8 de octubre de 2011.

** Estudiante de Derecho de la Universidad de Chile. Ayudante Ad honorem de las cátedras de Derecho Procesal, Derecho del Trabajo y de la Seguridad Social, Criminología y Ayudante de Investigación Ad honorem del Centro de Derechos Humanos de la Facultad de Derecho de la Universidad de Chile. Agradezco las observaciones que a un primer borrador realizaron Eduardo Achú Moscoso y Sebastián Pizarro Contreras, así como las sugerencias bibliográficas y comentarios del profesor Dr. Raúl Núnez Ojeda. No obstante lo anterior, cualquier error es de exclusiva responsabilidad del autor. Comentarios a franciscojara1@gmail.com. 


\section{PRELIMINARES ${ }^{1}$}

El propósito de estas páginas es dar algunos lineamientos para cuestionar una idea que parece haberse asentado sin muchas discusiones dentro de la cultura jurídica chilena, a saber, el progresivo establecimiento de reglas de exclusión probatoria en procesos no criminales.

Durante las últimas décadas, tanto en Chile como en sistemas comparados, las garantías fundamentales han comenzado a tomarse en serio para toda la actividad jurisdiccional del Estado. Dentro de estas garantías, podemos contar a la proscripción de la prueba ilícita, que impide que se admitan evidencias obtenidas con infracción de derechos fundamentales. Así, se trata de una institución con una promesa atractiva.

Pese a eso, nuestra doctrina, legislación y jurisprudencia no han visto inconvenientes en la creación de reglas similares a las del proceso penal en el ámbito de familia y civil, y reglas mucho más estrictas en el proceso laboral; a la par que la regla de exclusión se debilita progresivamente en materia penal.

Comenzaremos refiriéndonos al derecho a la prueba como parte integrante del derecho a la defensa, y en último término del debido proceso. Luego revisaremos las limitaciones que la doctrina ha identificado para este derecho, y entre ellas nos centraremos en la ilicitud de la prueba como una de estas barreras, precisando qué concepto de ilicitud probatoria sería compatible con el estándar de garantías judiciales de un Estado democrático de Derecho.

Por último revisaremos las normas de exclusión probatoria del CPP, la LTF, el CT y el PCPC de 2009, para terminar refiriéndonos a cuatro problemas sistemáticos, que tendrían estas normas; a saber: (i) su fundamentación; (ii) la idea de la exclusión como condición necesaria; (iii) su relación con los principios de cada rama del derecho; y (iv) el progresivo debilitamiento de la regla de exclusión en el proceso penal, a la inversa del ámbito civil. Este última situación aparece como la más problemática, pues implica con exigir a los privados un estándar idéntico o más exigente que a los agentes que detentan el poder punitivo del Estado.

\section{EL DERECHO A LA PRUEBA}

La conceptualización de la actividad probatoria ha experimentado un giro copernicano en las últimas décadas. De este modo, es pacífico en la doctrina afirmar que pasó de ser entendida como una simple carga procesal, a una ser comprendida como un derecho de relevancia

1 En estas páginas utilizaremos algunas abreviaturas normativas, la mayoría de ellas comunes en la práctica chilena. Así el Código Civil (CC), Código del Trabajo (CT), Código de Procedimiento Civil (CPC), Código Procesal Penal (CPP), la Constitución Política de la República (CPR), y la Ley 19.968 de Tribunales de Familia (LTF). Adicionalmente haré referencias al Anteproyecto (ACPC) y al Proyecto de Código Procesal Civil (PCPC) presentado a tramitación Mensaje No 398-357 de 2009, no obstante hoy se encuentra bajo revisión por la Comisión Intraministerial, integrada por el Ministro de Justicia y destacados académicos (y que debería darse a conocer durante este año). Estos documentos en: www.minjusticia.gob.cl. 
capital, en el contexto del reconocimiento de garantías procesales en constituciones y tratados internacionales ${ }^{2}$. Sea que se entienda en forma autónoma o como integrante de otras garantías, como el derecho a la defensa ${ }^{3}$, las definiciones de los autores coinciden en que este derecho consiste en "el derecho a influir sobre el convencimiento del juez"

En nuestro sistema es posible sostener que el derecho a la prueba se encuentra recogido por la Constitución (en adelante CPR), dentro de las garantías del art. $19 \mathrm{~N}^{\circ} 3$ incisos $2^{\circ} \mathrm{y}$ $5^{\circ}$, cuestión que ha sido recepcionada por la jurisprudencia de la Corte Suprema y el Tribunal Constitucional $^{5}$, lo que es armónico con las disposiciones de tratados internacionales de Derechos Humanos, tales como la Convención Americana sobre Derechos Humanos (art. 8), los cuales ingresarían a nuestro ordenamiento jurídico mediante el art. 5 inc. $2^{\circ}$ de la CPR, asegurando de este modo a los intervinientes de la actividad jurisdiccional un estándar de garantías compatibles con un Estado democrático de derecho. Por tanto se trataría de una condición "del debido proceso adjetivo" de impronta constitucional ${ }^{6}$.

Para la doctrina este derecho incluiría entre sus manifestaciones: (I) el derecho a poder participar en la realización de prueba y estar informados sobre ella; (II) a producir prueba dentro de un término probatorio; (iii) a hacerlo por medios idóneos de convicción; (iv) a pronunciarse sobre la pertinencia o relevancia de la prueba ofrecida, para evitar pruebas superfluas o prohibidas; (V) a examinar y contradecir la prueba aportada por la contraparte; (VI) a producir contraprueba; (VII) a discutir su eficacia ${ }^{7}$.

2 Taruffo, Michele. La prueba. Madrid, España: Marcial Pons, 2008, p. 56, Picó i Junoy, Joan. El derecho a la prueba en el proceso civil. Barcelona, España: J.M. Bosch Editor, 1996, p. 448.

3 Ferrer Beltrán, Jordi. "Derecho a la prueba y racionalidad de las decisiones judiciales", en: Jueces para la Democracia, n 47, pp. 27-34. Madrid, España: Asociación Jueces para la Democracia, 2003, p. 27.

4 Marinoni, Luiz Guilherme, Pérez Ragone, Álvaro, Núńez Ojeda, Raúl. Fundamentos del Proceso Civil. Hacia una teoría de la adjudicación. Santiago, Chile: Abeledo Perrot - Legal Publishing, 2010, pp. 280 y ss. Cfr. Taruffo, Michele. "Investigación Judicial y Producción de Prueba por las Partes", en: Revista de Derecho (Valdivia), vol. 15, n² 2, pp. 205-213. Valdivia, Chile: Facultad de Derecho, Universidad Austral de Chile, 2003, p. 209.; CArocca, Alex. La garantía constitucional de la defensa procesal. Barcelona, España: J. M. Bosch Editor, 1998, pp. 98-99.

5 CS, 05.01.2010. Rol № 7351-2009. Considerando séptimo. Para el caso del Tribunal Constitucional véanse: Rol № 808-07, 12 de agosto de 2008; Rol No 1393-09, 28 de octubre de 2010, Rol No 1411-09, 7 de septiembre de 2009, Rol No 1429-09, 2 de noviembre de 2010, todos sobre una limitación a las facultades de prueba en un caso de retención de tributos ante la Tesorería General de la República.

6 Marinoni, Luiz Guilherme, et. al., op. cit., p. 440.

7 Esta enumeración sigue a Andrés Bordalí y Alex Carocca, la recopilación en: Jara Bustos, Francisco. "La facilidad probatoria en el procedimiento de tutela laboral. Constitucionalidad y tramitación procesal", en: Revista Chilena de Derecho del Trabajo $y$ de la Seguridad Social, vol. 1, n² 2, pp. 153-184. Santiago, Chile: Departamento de Derecho del Trabajo y de la Seguridad Social, Facultad de Derecho, Universidad de Chile, 2010, pp. 162 y 163. 


\section{LOS LÍMITES DEL DERECHO A LA PRUEBA: LA CAUSAL DE ILICITUD}

Esta facultad de presentar todo medio de prueba para producir convicción, tiene al menos dos tipos de limitaciones, que surgen porque el derecho a la prueba no es absoluto como ningún principio ni regla, ya que exige el respeto de ciertas formalidades o garantías que constituyen los denominados "límites a la prueba". Entre estos podemos mencionar aquellos relativos a su pertinencia, relevancia o necesidad, que en la terminología de Joan Picó i Junoy correspondería a los "límites intrínsecos" a la actividad probatoria, y los referentes a la licitud de la prueba o "límites extrínsecos" " El criterio de pertinencia no plantea problemas desde la óptica del debido proceso ${ }^{10}$, sin embargo hay varias reglas de exclusión probatoria o privilegios que impiden a las partes utilizar todo el material relevante para la comprobación de sus afirmaciones sobre hechos.

De esta manera, para TARUfFo son criticables muchas de las limitaciones al derecho a la prueba que podemos encontrar en el derecho comparado debido a los intereses que estas protegerían, toda vez que se trata de un derecho "que tiene rango constitucional" 11 , y por ello, en la mayoría de los casos de conflicto, se debería decantar a favor de la admisión probatoria, debiéndose encontrar "un equilibrio favorable a la admisión de todas las pruebas relevantes de que dispongan las partes" 12 . De este modo el derecho a producir pruebas debería superar la mayoría de las ponderaciones, salvo aquellas que se dirijan a la salvaguardia de otros intereses especialmente relevantes; los que deberían reducirse a unos pocos, casos como sería, por ejemplo, "la protección de otro derecho constitucional o fundamental más importante" que tras la debida apreciación del tribunal permitiría sacrificar el derecho a la prueba ${ }^{13}$. De esta manera, se propendería a garantizar armónicamente el respeto de los derechos procesales de las partes, el resguardo de secretos relevantes y la búsqueda de la verdad en el proceso.

Teniendo esto en cuenta, podemos volver a nuestro problema. Dentro de las prohibiciones a la prueba es posible, entonces, proponer diversos tipos de intereses que justifican restringir

8 Véase el pionero trabajo: Carocca, Alex. "Una primera aproximación al Tema de la Prueba Ilícita en Chile", en: Ius et Praxis, vol. 4, n 2, pp. 301-322. Talca, Chile: Facultad de Derecho, Universidad de Talca, 1998, p. 305.

9 En diversos estudios el autor mantiene esta terminología. Los primeros "o inherentes a la actividad probatoria, son aquellos que necesariamente deben concurrir en la prueba para que pueda considerarse como tal, y son su pertinencia y utilidad" y los segundos "se derivan del carácter procesal de este derecho, y son aquellos exigidos por las normas de proposición con carácter general” para cualquier prueba o medio probatorio. (véase: Picó I Junoy, Joan. La prueba ilícita y su control judicial en el proceso civil. En: III Congreso Panameño de Derecho Procesal (16, 17, 18 y 19 de agosto de 2006, Ciudad de Panamá, Panamá). Ciudad de Panamá, Panamá: Instituto Colombo Panameño de Derecho Procesal, 2006, p. 160.

10 Así: TARuffo, Michele, op. cit. (n.2), p. 57.

11 Ibid.

12 Ibid., p. 58.

13 Ibid. En virtud del derecho a la prueba, en idéntico sentido razona Joan Picó I Junoy. (op. cit. (n.8), p. 159), y Alex Carocca (op. cit. (n.7), p. 307). 
el derecho a la prueba, y su admisibilidad dependerá de que la prohibición pueda fundarse constitucionalmente. En este caso nos centraremos en la antijuridicidad como causal de exclusión, también conocida como prueba ilícita.

Este es un tema que ha suscitado importantes discusiones en el derecho comparado, donde no pocos lo han puesto de manifiesto las ingentes dificultades que plantea la ilicitud probatoria; en un escenario donde ni aún la expresión prueba ilícita es demasiado precisa, su configuración doctrinal es variable, y capaz de suscitar vivaces polémicas.

La prohibición y exclusión de prueba ilícitas, tanto en Estados Unidos como en la cultura jurídica europea, principalmente se asocia al respeto de garantías procesales. Las mayores discusiones se han dado con ocasión del proceso penal por razones de su desarrollo histórico, donde la titularidad estatal de la persecución penal permitió el uso de medios probatorios que hoy nos parecerían lesivos de las mínimas garantías fundamentales ${ }^{14}$. Por esta razón los avances en la comprensión de los derechos de las personas buscaron convertir al proceso jurisdiccional en una garantía contra el riesgo de la extralimitación de los órganos persecutores en la búsqueda de la verdad ${ }^{15}$.

\section{I. El MOdelo de exClusión PRobatoria en los Estados Unidos}

Las teorías sobre la ilicitud de la prueba se encuentran fuertemente influidas por el Derecho norteamericano, que constituye un sistema de referencia obligatoria para otros países ${ }^{16}$. La exclusionary rule surge en "Weeks vs. United States, 232 U.S. 383, (I9I4)", por la aplicación que hiciera la Corte Suprema de los derechos contenidos en la IV Enmienda (derecho a no sufrir registros ni confiscaciones irrazonables). Otras prohibiciones se han fundamentado en vulneraciones a la V Enmienda (derecho a no declarar contra sí mismo), la VI Enmienda (derecho a la asistencia letrada), y la XIV Enmienda (derecho al debido proceso).

Si bien se trata de prohibiciones con fundamento constitucional, "tales derechos se constituyen en restricciones a la autoridad de los agentes públicos sobre los ciudadanos más que derechos individuales (deterrent effect)" ${ }^{17}$. Esto significa que la razón que tradicionalmente se ha esgrimido en Estados Unidos es la de disuadir el actuar ilegal de los órganos policiales, y no

\footnotetext{
14 Roxin, Claus. Derecho procesal penal-2a edición- Buenos Aires, Argentina: Editores del Puerto, 2003, pp. 563 y ss.

15 Especialmente véase: Roxin, Claus. "La protección de la persona en el derecho procesal penal alemán”. En su: La Evolución de la Politica Criminal, el Derecho Penal y el Proceso Penal. Valencia, España: Tirant lo Blanch, 2000, passim. Para el autor la jurisprudencia alemana ha sido sensata en la limitación de diversos temas como escuchas telefónicas, donde la ley calla, basándose en el desarrollo de los derechos fundamentales reconocidos por la Constitución Alemana y los tratados internacionales, aun cuando la nueva legislación cada vez disminuye más ciertas garantías.

16 Seguimos en esta sección a Armenta Deu, Teresa. La prueba ilícita (Un estudio comparado). Madrid, España: Marcial Pons, 2009, p.27.

17 Ibid., siguiendo a GómEZ-Jara.
} 
resguardar la eficacia de los derechos entre particulares, aun cuando estos se ven resguardados indirectamente. Por esto, en la jurisprudencia la exclusionary rule no entra en juego en caso de pruebas obtenidas ilícitamente por particulares ${ }^{18}$.

Han existido enfoques que se basan no sólo en impedir el actuar de los órganos estatales, sino en los problemas que tendría para el Estado quebrantar el derecho, que constituye el argumento de la integridad judicial (judicial integrity), sin embargo su carácter es más bien minoritario dentro de la jurisprudencia ${ }^{19}$. La doctrina del fruto del árbol envenenado surge como extensión de la exclusión a aquellas pruebas obtenidas a consecuencia de una infracción constitucional $^{20}$, sin embargo paulatinamente surgieron distintas excepciones a esta doctrina ${ }^{21}$.

Esto se hace más evidente si se revisa la última década donde se aprecia un declive de la exclusionary rule-“Hudson vs. Michigan 547 U.S. 586, (2006)"- basado en el mejor efecto que tendrían medidas civiles o disciplinarias para disuadir a los agentes estatales ${ }^{22}$.

\subsection{Tipología de PRUEBAS PROHibidas}

En contraste con el sistema de exclusión norteamericano, el modelo continental contempla sistemas de exclusión de carácter legal; los que además tienen incidencia también en procesos civiles, en sentido lato del término, es decir comprensivo de todas aquellas materias no criminales, como litigios civiles, mercantiles, laborales, de familia, etc.

Nuestro sistema -en la línea continental- se basa se basa en un reconocimiento legal de la ilicitud de la prueba, sin perjuicio de que el rol fundamental que competerá al juez en su apreciación, y en fijar distintas pautas para discernir en los casos límite, qué será y que no será considerado como prueba ilícita ${ }^{23}$. En vista de que nuestro ordenamiento ha consagrado pro-

18 Núńez Ojeda, Raúl. El Ofendido por el Delito y la Prueba en el Enjuiciamiento Criminal Español. En: Coloma, Rodrigo (ed.). La Prueba en el Nuevo Proceso Penal Oral. Santiago, Chile: Lexis-Nexis, 2002, p. 118.

19 De hecho, la regla de exclusión en principio no opera respecto de privados, salvo si ejercer una función púbica, como la seguridad privada, así: "Marsh vs. Alabama, 326 U.S. 501, (1946)".

20 “Silverthorne Lumber Co vs. United States, 251 U.S. 385, (1920)".Esta doctrina se originó cuando en un caso se impidió el testimonio ilegal de un testigo cuya existencia había sido descubierta por la incautación de un documento cuya obtención fue declarada ilegal en su obtención, y luego era imposible haber tenido conocimiento de este sujeto sin esa obtención ilegal (ZAPATA, María Francisca. La Prueba Ilícita. Santiago, Chile: Lexis-Nexis, 2004, p. 151).

21 Como la "doctrina de la fuente independiente" en la sentencia "Murray vs. United States, 487 U.S. 533, (1988)", la "regla del descubrimiento inevitable" con "Nix vs. Williams, 467 U.S. 431, (1984)", el "principio del vínculo atenuado" con "Nardone vs. United States, 308 U.S. 338, (1939)", la "excepción de buena fe" que se expresa en "United States vs. Leon, 468 U.S. 897, (1984)".

22 En este sentido: Armenta Deu, Teresa, op. cit., p. 31.

23 La importancia del juez es algo que la doctrina procesal más autorizada ha puesto de manifiesto (TARUfFo, Michele, op. cit. (n.2), passim), y es la tónica de nuestros procedimientos civiles reformados. 
gresivamente la apreciación libre de la prueba, en contraste al sistema legal tasado, el determinar la licitud o ilicitud de la prueba no tiene que ver con un medio o fuente de prueba específico, sino con una apreciación del "procedimiento cómo se consigue" 24 .

Respecto de qué vamos a considerar como prueba antijurídica se han propuesto variados conceptos y pese a no haber unanimidad, el que ha terminado por imponerse en nuestra tradición jurídica es "la fuente o elemento de prueba obtenido con infracción de determinadas normas o principios jurídicos" 25 . La mayor o menor amplitud con que entendamos este concepto está íntimamente ligado con el alcance que le daremos al derecho a la prueba, por lo que delimitar el concepto es de suma importancia.

Entre los muchos criterios se cuentan, sin ánimo de exhaustividad, la prueba prohibida, prueba ilegítima, prueba irregular -también llamada ilegal-, prueba clandestina o bien de prueba ilícita, no siendo estos conceptos necesariamente excluyentes entre $s^{26}$. Respecto de las prohibiciones probatorias estas hacen referencia a distintos supuestos de prueba indebida, afectando tanto "a la adquisición de las fuentes de prueba, como a los medios probatorios a través de los cuales dichas fuentes se introducen en proceso" 27 .

La prueba ilegal estaría constituida por "toda aquella obtenida o practicada con vulneración de preceptos que no gozan del carácter de normas constitucionales que reconocen derechos fundamentales"28. Existen confusiones con la llamada prueba ilegítima, formulación doctrinal italiana, que atiende al carácter de las normas, distinguiendo entre aquellas que vulneran normas sustantivas o procesales, siendo las primeras susceptibles de valoración, y las que vulneran normas procesales siempre ilegítimas y nulas ${ }^{29}$.

24 Gozaíni, Osvaldo. Obtención y Valoración de la Prueba Ilícita. En: De la Oliva Santos, Andrés, Palomo Vélez, Diego (coords.). Proceso Civil. Hacia una nueva justicia civil. Santiago, Chile: Editorial Jurídica de Chile, 2007, p. 337. Así por ejemplo la confesión, o el uso de cintas magnetofónicas son medios de prueba autorizados (se permite cualquier medio de prueba destinado a formar convicción), sin embargo no lo sería la confesión obtenida a través de apremios ilegítimos, grabación subrepticia de conversaciones.

25 Carocca, Alex, op. cit. (n.7), p. 307. Otro autor muestra un ejemplo histórico de un criterio amplísimo de ilicitud moral lo podemos encontrar en un proyecto de la LEC de 1881 que prescribía: "El tribunal no admitirá los medios de prueba que se hayan obtenido por la parte que los proponga o por terceros empleado procedimientos que a juicio del mismo se deban considerar reprobables según la moral o atentatorios contra la dignidad de la persona". Así: GonZALes García, Jesús María. "El Proceso Penal Español y La Prueba Ilícita”, en: Revista de Derecho (Valdivia), vol. 18, n² 2, pp. 187-211. Valdivia, Chile: Facultad de Derecho, Universidad Austral de Chile, 2005, pp. 190 y ss.

26 Hemos excluido mencionar la prueba viciada, que se refiere más bien a la veracidad o certeza de los datos fácticos que aporta, y no a su ilicitud o ilegalidad (cfr. GOZAÍNI, Osvaldo, op. cit., p. 343). CAROCCA, Alex, op. cit. (n.7), p. 309.

27 Carocca, Alex, op. cit. (n.7), p. 309.

28 Ibid.

29 Ibid., p. 310. 
La prueba clandestina sería "aquella que se obtiene a través de un comportamiento oculto o de un acto realizado sin publicidad, es decir, aquella que se lleva a cabo de un modo solapado, infringiendo la intimidad o privacidad de las personas" 30 . En el fondo se trata de actos atentatorios contra la intimidad, personal o familiar, la imagen, etc.

La prueba ilícita de acuerdo con Alex CAROcca se definiría como:

"aquella obtenida con infracción de cualquier derecho fundamental, reconocido a nivel constitucional en nuestro país, ya sea directamente o por remisión a los tratados internacionales sobre Derechos Humanos"31.

En derecho comparado Joan PICÓ I JUNOY ha propuesto conceptualizarla como:

“aquella cuya fuente probatoria está contaminada por la vulneración de un derecho fundamental o aquella cuyo medio probatorio ha sido practicado con idéntica infracción de un derecho fundamental"32.

Las definiciones recién expuestas dan cuenta en general de una tendencia que se observa en el derecho comparado, y que hace que hoy en día la definición de prueba ilícita más aceptada sea "aquella obtenida con inobservancia de garantías fundamentales"33. Dogmáticamente esta concepción se conoce como criterio restringido de prueba ilícita, y en general no distingue si los derechos o garantías fundamentales se encuentran consagrados por normas constitucionales, tratados internacionales, o normativa de menor jerarquía. Esta se opone al criterio amplio, que considera en como ilícita aquella prueba contraria a una norma de derecho, con independencia de su categoría o naturaleza ${ }^{34}$.

Esta definición centrada en la inobservancia de garantías fundamentales prima facie nos parece la más correcta atendida la relevancia que debe asignársele al derecho a la prueba. También, a partir de las diversas definiciones de pruebas prohibidas, al no ser necesariamente

0 Gozaíni, Osvaldo, op. cit., p. 343.

31 Carocca, Alex, op. cit. (n.7), p. 308.

32 Picó i Junoy, Joan, op. cit. (n.8), p. 160. El citado autor extrae esta definición a partir de su legislación, a saber de los arts. 11.1 de la LOPJ y del 287 LEC. A su juicio la prueba ilegal es plenamente admisible en el ordenamiento español, pues el Tribunal Constitucional Espańol en sentencia 114/1984 declaró la inexistencia de una norma que imponga la ineficacia procesal de pruebas obtenidas antijurídicamente, por lo que a priori es posible admitirla en juicio.

33 Honvitz, María Inés y López, Julián. Derecho Procesal Penal Chileno. Tomo II. Santiago, Chile: Editorial Jurídica de Chile, 2004, p. 169. Esta definición es seguida, en términos generales, en: Ferrada, Francisco. La prueba ilícita en sede civil. Tesis (Para optar al grado de Magíster en Derecho) Santiago, Chile: Universidad de Chile, Facultad de Derecho, 2009 , p. 14.

34 Esta distinción es reconocida por: Midón, Marcelo. Pruebas Ilícitas. Análisis Doctrinario y Jurisprudencial. Mendoza, Argentina: Ediciones Jurídicas de Cuyo, 2002, pp. 33 y ss. En el mismo sentido: Miranda Estrampes, Manuel. El concepto de prueba ilícita y su tratamiento en el proceso penal. Barcelona, Espańa: J. M. Bosch Editor, 2004, pp. 22 y ss. Debe recordarse que no necesariamente todas las garantías fundamentales se encuentran en normas de la Constitución Política, por ejemplo muchas de las garantías procesales se encuentran en el del Título I del Libro Primero del Código Procesal Penal; del mismo modo la normativa de los arts. 2 y 5 constituyen ejemplos de garantías fundamentales establecidas en leyes, no obstante en último término definitiva son concreciones de mandatos del art. 19 CPR, o de disposiciones de Tratados Internacionales sobre Derechos Humanos. 
excluyentes entre sí, podemos decir que en la práctica la prueba viciada sería reconducible a hipótesis de prueba que vulnera derechos fundamentales. Asimismo la distinción de prueba ilegítima, si bien dogmáticamente bien delimitada, puede resultar impráctica o inoperante en un ordenamiento jurídico, pues la vulneración de derechos fundamentales puede ser independiente del momento extra o intra procesal en que haya tenido lugar, y de la procedencia de la norma ${ }^{35}$.

Hasta aquí hemos visto algunas de las principales categorías de pruebas antijurídicas. Los autores coinciden en que su obtención importa en la mayoría de los casos sanciones de distinta intensidad respecto de su eficacia probatoria que van desde la imposibilidad de su apreciación hasta su apreciación atenuada.

\section{MANIFESTACIONES DE LA EXCLUSIÓN POR ILICITUD DE LA PRUEBA ILÍCITA EN EL DERECHO CHILENO}

La prueba ilícita como tal no se encuentra nombrada como institución en la legislación nacional, sino que desde las reformas a la justicia chilena, que comenzaron con la Reforma Procesal Penal, se establecieron reglas de exclusión de prueba obtenida con vulneración de garantías fundamentales inspirado por el sistema de los Estados Unidos ${ }^{36}$.

\section{I. LA REgLA DE EXCLUSIÓN EN EL PROCESO PENAL}

La regla de exclusión fue consagrada normativamente en nuestro sistema jurídico en el artículo 276 del CPP en su inciso tercero:

Art. 276 CPP. "Exclusión de pruebas para el juicio oral. El juez de garantía, luego de examinar las pruebas ofrecidas y escuchar a los intervinientes que hubieren comparecido a la audiencia, ordenará fundadamente que se excluyan de ser rendidas en el juicio oral aquellas que fueren manifiestamente impertinentes y las que tuvieren por objeto acreditar hechos públicos y notorios.

$(\ldots)$

Del mismo modo, el juez excluirá las pruebas que provinieren de actuaciones o diligencias que hubieren sido declaradas nulas y aquellas que hubieren sido obtenidas con inobservancia de garantías fundamentales.

\footnotetext{
35 Esta distinción empero, ha sido utilizada en nuestra práctica jurídica, así en un oficio del Ministerio Público sobre prueba ilícita, se identifica esta con la vulneración de garantías procesales, y la ilegal respecto de normas procesales de carácter formal. (PiEDRABUENA Richard, Guillermo. Orienta a los fiscales en el tema de exclusión de la prueba ilícita. \En línea囚 Oficio del Ministerio Público N 167. Santiago, abril 2002 [Citado 20 enero 2011] Disponible en World Wide Web: <www.ministeriopublico.cl>.

36 Así concluyen en su estudio comparado Armenta Deu, Teresa, op. cit., pp. 43 y ss.
} 
Las demás pruebas que se hubieren ofrecido serán admitidas por el juez de garantía al dictar el auto de apertura del juicio oral" (el destacado es nuestro).

\subsection{Manifestaciones de la Regla de exclusión probatoria en procesos civiles}

Desde el CPP diversas legislaciones han consagrado garantías en el mismo sentido, entre ellas el artículo 31 de la Ley de Tribunales de Familia (en adelante LTF):

Art. 31 LTF. Exclusión de prueba. El juez de familia, luego de estudiar la admisibilidad de las pruebas ofrecidas, de resolver las convenciones probatorias y de escuchar a las partes que hubieren comparecido a la audiencia preparatoria, ordenará fundadamente que se excluyan de ser rendidas en el juicio aquellas que fueren manifiestamente impertinentes, tuvieren por objeto acreditar hechos públicos y notorios, resulten sobreabundantes o hayan sido obtenidas con infracción de garantías fundamentales. Las demás serán admitidas y se ordenará su rendición en la audiencia de juicio respectiva. (El destacado es nuestro).

Con la reforma al proceso laboral la prueba ilícita por primera vez fue reconocida por la legislación procesal laboral en el art. $453 \mathrm{~N}^{\circ} 4$, inc. $4^{\circ}$ del Código del Trabajo (en adelante, CT):

Art. 453 CT. En la audiencia preparatoria se aplicarán las siguientes reglas:

4) El juez resolverá fundadamente en el acto sobre la pertinencia de la prueba ofrecida por las partes, pudiendo valerse de todas aquellas reguladas en la ley.

$(\ldots)$

Sólo se admitirán las pruebas que tengan relación directa con el asunto sometido al conocimiento del tribunal y siempre que sean necesarias para su resolución.

Con todo, carecerán de valor probatorio y, en consecuencia, no podrán ser apreciadas por el tribunal las pruebas que las partes aporten y que se hubieren obtenido directa o indirectamente por medios ilícitos o a través de actos que impliquen violación de derechos fundamentales.

En CPC no contiene una norma sobre prueba ilícita, sin embargo en el Proyecto de Código Procesal Civil (PCPC de 2009) se contemplaba la exclusión de pruebas, y en concreto aquella por vulneración de garantías fundamentales. Si bien hoy en día el proyecto está en ma- 
nos de la Comisión Intraministerial, tenemos razones para pensar que al menos en lo sustantivo la regulación se mantendrá idéntica por la experiencia de la discusión parlamentaria de las normas anteriores ${ }^{37}$, como la discusión de la reforma Procesal Civil ${ }^{38}$ :

Art. 263 PCPC. Exclusión de prueba. El juez, ordenará fundadamente que se excluyan de ser rendidas en el juicio aquellas pruebas que fueren manifiestamente impertinentes, tuvieren por objeto acreditar hechos públicos y notorios, resulten sobreabundantes, hayan sido obtenidas con infracción de garantías fundamentales o recaigan sobre hechos no controvertidos, a menos que se tratare de cuestiones indisponibles para las partes.

Las demás serán admitidas y se ordenará su rendición en la audiencia de juicio respectiva.

La comparación evidencia, que aunque en la legislación no existe un concepto único de exclusión probatoria, en la práctica se impone el elemento común basado en la "inobservancia de garantías fundamentales"39, salvo en materia laboral.

37 Las razones que tenemos para esto no son meramente intuitivas, sino que se basan en que las reglas procesales que contemplan exclusión por regla general no son objeto de gran discusión parlamentaria. En la LTF, si bien el proyecto de ley original -Mensaje No 81-336- no contempló la exclusión probatoria, durante el Primer Trámite Constitucional en la Cámara de Diputados contemplo por sugerencia del Presidente de la República la actual redacción de la norma (Historia de la Ley No 19.968. Biblioteca del Congreso Nacional. 30 de Agosto de 2004. Disponible en <www.bcn.cl>, p. 973), lo que se aprobó durante el Segundo Informe de la Comisión de Constitución pasando a constituir el art. 31 LTF (Ibíd., p. 1072), sin volver a ser discutido. En la Reforma a la Justicia Laboral el Mensaje $\mathrm{N}^{\circ}$ 4-350 se expresa sobre los medios de prueba que "de manera novedosa, se incorpora en el proyecto una regla dirigida a privar de valor probatorio a las pruebas que las partes aporten y que se hubieren obtenido directa o indirectamente por medios ilícitos o a través de actos que impliquen violación de derechos fundamentales" (Historia de la Ley No 20.087. Biblioteca del Congreso Nacional. 03 de Enero de 2006. Disponible en <www.bcn.cl>. p. 18), lo que se tradujo en el art. 458 inc. $4^{\circ} \mathrm{CT}$ que consagra la misma regla de exclusión del actual 453 CT (Ibíd., pp. 37-38), y se aprobó en el Primer Informe de la Comisión de Trabajo por unanimidad (Ibíd., p. 103). En el primer Boletín de Indicaciones del Senado, en la indicación 122, el Senador Boeninger propuso eliminar la frase final "o a través de actos que impliquen violación de derechos fundamentales" (Ibíd., p. 492), moción rechazada en el Segundo Informe de la Comisión de Trabajo (Ibíd., p. 600), de ahí en más continuó el texto como lo conocemos a ser el art. $453 \mathrm{~N}^{\circ} 5$ inc. $3^{\circ}$. Su actual ubicación se debe a la llamada "reforma de la reforma", donde la regla no fue objeto de discusión y pasó a la ubicación que conocemos del art. $453 \mathrm{~N}^{\circ} 4$ inc. $4^{\circ}$ (Historia de la Ley No 20.260. Biblioteca del Congreso Nacional. 29 de Marzo de 2008. Disponible en <www.bcn.cl>, p. 84).

38 El análisis de esto muestra que hay una tendencia a mantener la regulación de la prueba ilícita. El ACPC elaborado por la Universidad de Chile contemplaba en su Art. 267 N $^{\circ} 7$ sobre el "Contenido de la Audiencia Preliminar", que una de estas es "Excluir de ser rendidas en el juicio aquellas pruebas que fueren manifiestamente impertinentes, tuvieren por objeto acreditar hechos públicos y notorios, resulten sobreabundantes o hayan sido obtenidas con infracción de garantías fundamentales. Las demás serán admitidas y se ordenará su rendición en la audiencia de juicio respectiva”. Esta formulación es recogida con una formulación prácticamente idéntica en el art. $254 \mathrm{~N}^{\circ} 8$ del PCPC. El art. 282 APCP, sobre "exclusión de prueba" contiene una enunciación que es idéntica, con algunos cambios estilísticos a la del PCPC. En el Informe del Foro Procesal Civil, que se encuentra en el sitio web del Ministerio de Justicia no hay grandes discusiones respecto de esto, sino menciones que no discuten el fondo (p. 311).

39 La fórmula garantías fundamentales es la expresión más utilizada, a saber, los arts. 276 CPP, 31 LTF y 263 del PCPC. El art. $453 \mathrm{~N}^{\circ} 4$ CT, usa la formulación derechos fundamentales, pero debe entenderse sinónima. 


\section{PROBLEMAS DE INTERPRETACIÓN DE LA PRUEBA ILÍCITA EN EL DERECHO CHILENO}

Con los diez años que, aproximadamente, lleva operando la regla de exclusión probatoria del nuevo proceso penal, ésta ha debido hacer frente a diversos problemas interpretativos que han sido abordados por un prurito doctrinario y jurisprudencial. Comprenderlos resulta muy relevante, toda vez, que mutatis mutandis pueden decir mucho sobre la problemática de este tipo de reglas en procesos entre particulares.

Hemos identificado, entre otros, los siguientes debates relevantes, e intentaremos exponer por qué en nuestra opinión la regulación de la prueba ilícita en el derecho chileno adolece de serios problemas sistemáticos. Comenzaremos por la discusión que se ha suscitado en materia penal, y su utilidad para comprender las reglas de los procesos de familia y laboral $-\mathrm{y}$ al PCPC de 2009 si correspondiere-, o evidenciar su falta de coherencia ${ }^{40}$.

(I) Primer Problema: La fundamentación de la regla

(I.I). CPP: La doctrina y la jurisprudencia comparten ampliamente el sustento de esta regla considerando la eficacia de los derechos fundamentales contra el poder punitivo del Estado, lo que se encuentra además respaldado por el derecho al debido proceso, art. $19 \mathrm{~N}^{\circ} 3$, y el art. 5 inc. $2^{\circ}$ de la CPR que integra una serie de garantías judiciales de tratados internacionales sobre Derechos Humanos ${ }^{41}$. De esta forma, se trata de un caso paradigmático de eficacia vertical de los derechos fundamentales como límite al poder punitivo del Estado.

(I.II). LTF, CT y PCPC: La idea de la eficacia horizontal de los derechos fundamentales entre particulares o "efecto horizontal" de los mismos, como ha indicado aldunate es un fenómeno "aceptado sin discusión" y -a menudo- "sin mayor reflexión" en nuestro país ${ }^{42}$, a partir del art. 6 inc. $2^{\circ} \mathrm{CPR}$, y de la normativa de la acción de protección (art. $20 \mathrm{CPR}$ ), lo que tendría un efecto desastroso sobre la libertad de las personas y desdibujan la noción clásica de derechos fundamentales como límites al Leviatán ${ }^{43}$. Debe atenderse también que, aunque con particularidades propias, las reglas del CT, la LTF -y de un futuro ordenamiento Procesal Civ -son procedimientos donde ambas partes son titulares de derechos fundamentales, a diferencia del proceso penal, no obstante los cuestionamientos por la "posible disparidad de recursos materiales existentes entre las partes" ${ }^{4}$.

40 No obstante que haremos precisiones en caso de las diferencias entre la LTF, el CT y el PCPC.

41 Sobre el punto revisar Zalaquett, José y Nash Claudio. "Proceso Penal y Derechos Humanos", en: Revista de Derecho Procesal, vol. 20, pp. 61-97. Santiago, Chile: Departamento de Derecho Procesal, Facultad de Derecho, Universidad de Chile, 2005, pp. 68 y 69.

42 Aldunate, Eduardo. Derechos Fundamentales. Santiago, Chile: Legal Publishing, 2008, p. 212.

43 Atria, Fernando. "Ubi Ius, Ibi Remedium? La Relevancia Jurídica de los Derechos Humanos", en: Revista de Estudios de la Justicia, ${ }^{\circ} 12$, pp. 35-47. Santiago, Chile: Centro de Estudios de la Justicia, Facultad de Derecho, Universidad de Chile, 2003, p. 37.; y en general la obra de este autor.

44 Ferrada, Francisco, op. cit., p. 34. 
En este sentido, ambas partes del proceso de familia, o del proceso laboral detentan -entre otros- el derecho a la prueba, por lo que necesariamente las limitaciones deben entenderse de la manera más restringida posible como sostiene la doctrina más autorizada, nacional y comparada. Esto vuelve inexplicable el estándar existente en materia laboral, toda vez que no sólo es comprensivo de la "prueba ilícita" en sentido restringido ${ }^{45}$, sino también de la llamada "prueba ilegal”, y amplia todavía más esta regla de prueba ilegal, al señalarla como aquella obtenida "directa o indirectamente", lo que en principio podría constituir una recepción normativa de la "teoría de los frutos del árbol envenenado" 46 , lo que nos resulta problemático, pues extiende la prohibición a niveles desconocidos en nuestro ordenamiento jurídico.

Esta concepción amplísima de la prueba ilícita puede permitir que incluso se excluya una prueba por la vulneración de un reglamento interno de la empresa, debido a la formula omnicomprensiva que emplea. Ahora, debemos intentar encontrar justificaciones para esta regla, y efectivamente veremos que existen argumentos fuertes a considerar:

(I.I) El primero de estos es el conocido carácter tutelar del derecho del trabajo, y entre otras normas el art. 5 CT que enfatiza el deber de respeto a las garantías fundamentales del trabajador. Sería injusto desconocer que el derecho del trabajo por esta especial característica ha sido pionero en el ámbito de la reflexión de los derechos fundamentales entre particulares ${ }^{47}$, y en concreto en materia de ilicitud probatoria en importantes ordenamientos comparados. En el derecho español -señala JEQUIER- prueba de que el proceso penal no monopoliza estas reflexiones, "es que el primer pronunciamiento del Tribunal Constitucional español -TC- sobre esta cuestión fue en relación con un asunto incardinado en un proceso laboral y no penal" 48 .

Si bien se trata de un argumento a considerar, sistemáticamente parece problemático dado que el carácter protector no es privativo de las relaciones laborales, sino también se encuentra en el derecho de familia y en los principios de la LTF. Se violenta así, la igualdad ante la ley al establecer estándares tan disímiles de aceptación de prueba.

45 Es decir, como revisamos, la que se obtiene sólo con vulneración de garantías fundamentales.

46 Así lo ha entendido Cabezas Pino, René. Aspectos relevantes de la prueba en el nuevo proceso laboral. Tesis (Para optar al grado de licenciado en Ciencias Jurídicas y Sociales). Santiago, Chile: Universidad de Chile, Facultad de Derecho, 2010, pp. 82-83.; -y sobre la base de una redacción similar al art. 11.1 de la Ley Orgánica del Poder Judicial (LOPJ) español- Melis VAlencia, Christian. Los derechos fundamentales de los trabajadores como limites a los poderes empresariales. Santiago, Chile: Abeledo Perrot - Legal Publishing, 2009, p. 81. En el mismo sentido -en la doctrina española mayoritaria sobre el art. 11 LOPJ se puede citar a MirANDa Estrampes, Manuel, op. cit., pp. 27 y 28. Cfr. a Picó i Junoy, Joan, op. cit. (n.9), pp. 165 y ss., para quién la LOPJ no haría extensible esos efectos considerando el Derecho a la Prueba que garantiza el art. $24 \mathrm{~N}^{\circ} 2$ de la Constitución Espańola.

47 Jana Linetzky, Andrés, La eficacia horizontal de los derechos fundamentales. En: VV.AA., Los derechos fundamentales. Seminario Latinoamérica de Teoría Constitucional 2001. Buenos Aires, Argentina: Editores del Puerto, 2003. El autor destaca que una cosa análoga ha ocurrido en el derecho de familia.

48 Jequier, Eduardo. "La obtención ilícita de la fuente de la prueba en el proceso civil. Análisis comparativo del ordenamiento jurídico español y chileno", en: Revista Chilena de Derecho, vol. 34, n 3, pp. 457-494. Santiago, Chile: Facultad de Derecho, Universidad Católica de Chile, 2007, p. 460. El pronunciamiento del Tribunal Constitucional Español es: STC 114/1984, de 29 de noviembre. 
(I.II)Permite evitar discusiones doctrinarias como las del derecho comparado. Al revisar las teorías norteamericanas de exclusión de la prueba (y de limitación a la regla de exclusión), podemos ver que esta regla puede constituir una forma de terciar el debate. En este sentido René CABEZAS PINO celebra que esta regla permitiría "evitar la discusión doctrinaria sobre la extensión de la regla de exclusión de la prueba derivada de un ilícito, proporcionando una solución legal, sin que exista necesidad de una salida jurisprudencial a la controversia como ocurrió en muchos países" ${ }^{39}$. Como crítica puede mencionarse que los jueces igualmente podrían modular estas reglas, o darles excepciones, como las que ha encontrado la teoría de los frutos del árbol envenenado en el derecho norteamericano.

(I.III) Un tercer argumento a considerar puede ser principio de buena fe procesal que establece el nuevo art. 425 CT, y que tienden a considerar que el proceso, aunque disputa de intereses, no permite utilizar cualquier medio para lograr un resultado. Como se ha afirmado en otro lugar, "si no se está de acuerdo con estas concepciones de una lucha leal -que permitirían justificar las cargas probatorias dinámicas- dejaría de tener sentido la idea de exclusión de la prueba ilícita" ${ }^{50}$. Este nos parece uno de los argumentos más sostenibles. Sin embargo, podríamos criticarlo si pensamos que la buena fe procesal, por mucho que puede ser un argumento que apoya la exclusión probatoria -pues su fundamento último son las garantías fundamentales-, no explicaría a cabalidad la exclusión probatoria, y de aprobarse disposiciones sobre buena fe procesal, como muy seguramente ocurrirá, y las normas de exclusión probatoria de la nueva legislación procesal civil se mantienen, estaríamos en presencia de otro problema de coherencia.

(I.IV) El inusual diseño de la regla del CT, podría deberse a la deliberación del parlamento, sin embargo por lo que enunciamos de las actas, el texto de la norma venía así desde el mensaje presidencial, y como señalamos, la única indicación para modificar el artículo del Senador BOENINGER tenía por objeto eliminar la prueba ilícita por vulneración de garantías fundamentales; iniciativa que no prosperó. La filiación intelectual de la norma en el proyecto presidencial también es un misterio, ya que ni siquiera el Foro para la Reforma a la Justicia Laboral y Previsional ${ }^{51}$ contemplaba una idea de exclusión tan amplia, sino que se centraban en la definición de prueba ilícita restringida, con visos de la "teoría del fruto del árbol envenenado" 52.

\footnotetext{
Cabezas Pino, René, op. cit., p. 85.

Jara Bustos, Francisco, op. cit., p. 176, siguiendo a Masciotra.

51 Esta entidad, integrada por personalidades de distintas esferas vinculadas al Derecho del Trabajo diseñó una propuesta de reforma. En 2002 se entregó al Ministerio de Justicia el documento "Bases Fundamentales para la Reforma de la Justicia Laboral y Previsional que, a su turno, debería servir de base del proyecto de reforma. (Consúltese: Walter, Rodolfo y Lanata, Gabriela. Régimen legal del nuevo proceso laboral chileno -6a edición- Santiago, Chile: Legal Publishing, 2009, pp. 24 y ss.

52 Dentro del apartado 2.1 Letra C, podemos encontrar: "En materia de medios de prueba, debe autorizarse a las partes para valerse de cuantos medios de prueba se encuentren regulados en la ley, admitiéndose como tales los medios mecánicos de reproducción de la palabra, de la imagen y del sonido, salvo que se hubieran obtenido, directa o indirectamente, mediante procedimientos que supongan violación de derechos fundamentales y libertades públicas" (el destacado es nuestro). Bases Fundamentales para la Reforma de la Justicia Laboral y Previsional. Disponible en <www.cejamericas.org>, p. 32.
} 
(II) Segundo Problema: ¿Es la regla de exclusión condición necesaria?

(II.I). CPP: Sobre lo expuesto en (I), relativo a la legislación procesal penal como manifestación paradigmática de la eficacia vertical de los derechos fundamentales, se ha sostenido -acertadamente a nuestro juicio- que la nula consagración de reglas de esta tipo en el Código de Procedimiento Penal o en otro cuerpo normativo no impediría solicitar la exclusión de prueba obtenida o incorporada al proceso ilícitamente ${ }^{53}$, basado en los arts. 5 y 6 de la CPR. Estas disposiciones consagran los principios de supremacía constitucional y de vinculación directa de la Constitución, lo que haría aplicable prohibiciones probatorias en nuestro ordenamiento aún en caso de no existir consagración normativa expresa, dado que un sector importante de la literatura constitucional clásica, entiende que pese a que la CPR no consagra todos los derechos que se pueden vulnerar por la prueba ilícita, estos se deben entender incorporados (art. 5 CPR) y serían vinculantes para particulares (art. $6 \mathrm{CPR})^{54}$. Aún este enfoque permitiría que la prueba ilegal, en principio, pudiera ser valorada libremente, debiendo sancionarse a los infractores con la sanción civil, administrativa o penal pertinente.

(II.II). LTF, CT y PCPC: Aun cuando la literatura constitucional tradicional permitiría sostener un efecto similar por el sólo art. 6 CPR, hay que ser cautos a la hora de limitar el derecho a la prueba sin norma expresa. El estándar aplicable al proceso penal, en buenas cuentas prohíbe al aparato del Estado actuar con racionalidad estratégica y lo obliga a respetar los derechos fundamentales de la persona. En la actual regulación del Código de Procedimiento Civil no existe norma sobre el particular, pero existen opiniones mayoritarias en la doctrina a favor de la exclusión ${ }^{55}$. Jurisprudencialmente previo a la reforma a la justicia laboral se ha reconocido la exclusión de prueba por vulneración de garantías fundamentales, porque su obtención -al vulnerar la esfera de intimidad del trabajador- no constituiría una investigación racional y justa contra lo dispuesto en el art. $19 \mathrm{~N}^{\circ} 3 \mathrm{y} \mathrm{N}^{\circ} 4 \mathrm{CPR}^{56}$.

53 EcheVerría, Isabel. Los derechos Fundamentales y la Prueba Ilícita. Con especial referencia a la prueba ilícita aportada por el querellante particular y por la defensa. Tesis (Para optar al grado de licenciado en Ciencias Jurídicas y Sociales). Santiago, Chile: Universidad de Chile, Facultad de Derecho, 2007, pp. 92 y ss.; Zapata, María Francisca, op. cit. pp. 46-50.

54 Cea Egaña, José Luis. Derecho constitucional chileno. Santiago, Chile: Ediciones de la Universidad Católica de Chile, 2008, p. 244 y ss.

55 Maturana, Cristián. Aspectos Generales de la Prueba. Apuntes de Derecho Procesal II. Santiago, Chile: Departamento de Derecho Procesal, Facultad de Derecho, Universidad de Chile, 2006.

56 Octavo Juzgado de Letras del Trabajo de Santiago, Rol N 4862-2001, y el fallo de la Corte de Apelaciones de Santiago de 13.11.2006, Rol No 1954-2006. Citadas en: Ferrada, Francisco, op. cit., p. 87. También se ha argumentado a partir de la declaración por medio de una acción de protección de que ciertos medios de vigilancia a los trabajadores vulneran sus derechos fundamentales, debería necesariamente obligar a que los tribunales no valoren ese medio de prueba. Este último fundamento parece feble, toda vez se cita más bien reconocimientos de derechos iusfundamentales en el ámbito de una acción constitucional y no fallos de los tribunales del trabajo. Véase: Walter, Rodolfo y Lanata, Gabriela, op. cit., pp. 207-208. En el mismo sentido Cabezas Pino, René, op. cit., pp. 84-85. 
Con todo, otras opiniones sostienen que la falta de regulación debería dar lugar a la admisión de la prueba en la mayoría de los $\operatorname{casos}^{57}$, considerando el derecho a la prueba de las partes, sin perjuicio de las sanciones que en derecho correspondan por vulneraciones materiales; y por supuesto siempre excluyendo aquellas producto de vulneraciones que sean especialmente graves.

Lo problemático de esta excepción tan vaga, es que si uno piensa cuál es el caso de una vulneración de tal gravedad, se trata de la confesión obtenida mediante tortura. Ésta, en todo caso, se encuentra prohibida por tratados como la Convención contra la Tortura y Otros Tratos o Penas Crueles, Inhumanos o Degradantes de 1984 (art. 15), y la Convención Interamericana para Prevenir y Sancionar la Tortura de 1985 (art. 10), entre otros ${ }^{58}$; sin embargo existen casos menos evidentes y aberrantes de vulneración de garantías fundamentales, donde la discusión parece buscar otro tipo de salidas.

En este sentido podemos citar a Jorge Larroucau, quién ha sostenido que "la exclusión de pruebas ilícitas o, más amplio todavía, irregulares, en tanto que afectan una cuestión valiosa que merece protección jurídica, configura unade las alternativas que el proceso civil puede contemplar según las circunstancias del caso" 59 . De este modo sería posible proponer opciones a la regla de exclusión como “(a) imponer sanción administrativa, (b) emplear el tipo criminal que corresponda y (c) otorgar indemnización civil" 60 o realizar las combinaciones pertinentes de estos elementos. El autor cita interesantes fallos, uno de Estados Unidos, otro de Inglaterra donde la responsabilidad civil y la buena fe permiten imponer costas por transgresiones a la buena fe ${ }^{61}$. También llama la atención un fallo de la Corte de Apelaciones de Rancagua donde en lugar de excluirse las evidencias, se opta por la responsabilidad civil del actor que las produjo ${ }^{62}$.

Debemos notar que aunque el autor cree que es posible argumentar en favor de la exclusión en este caso por haber una actitud dolosa, lo destacable del veredicto es la forma "cómo se conjugan diversos aspectos como son la búsqueda de hechos verdaderos, la buena fe procesal, la

57 Carocca, Alex, op. cit. (n.7), p. 319.

58 Artículo15. "Todo Estado Parte se asegurará de que ninguna declaración que se demuestre que ha sido hecha como resultado de tortura pueda ser invocada como prueba en ningún procedimiento, salvo en contra de una persona acusada de tortura como prueba de que se ha formulado de declaración".

Art. 10. "Ninguna declaración que se compruebe haber sido obtenida mediante tortura podrá ser admitida como medio de prueba en un proceso, salvo en el que se siga contra la persona o personas acusadas de haberla obtenido mediante actos de tortura y únicamente como prueba de que por ese medio el acusado obtuvo tal declaración".

59 Larroucau Torres, Jorge. La prueba en el proceso civil. Tesis (Para optar al grado de Doctor en Derecho) Santiago, Chile: Universidad de Chile, Facultad de Derecho, 2010, p. 163.

$60 \quad$ Ibid, p. 168.

$61 \quad$ Ibid, pp. 169 y 171.

62 Corte de Apelaciones de Rancagua. 01.04.2008, Rol N 592-2007, cons. 5. Citado por Ibíd. p. 170. 
relevancia y la inclusión de pruebas"63. Incluir estos elementos en el debate ciertamente aportará mejores reflexiones que dejarnos llevar por el neoconstitucionalismo nacional ${ }^{64}$ y al mismo tiempo, sería posible aplicar la racionalidad de cada rama integrante del derecho privado.

(III) Los principios del Proceso Penal: el caso de la prueba de descargo

(III.I) CPP: Las reflexiones de los apartados (I) y (II) merecen una consideración, pues aun cuando el tenor del art. $276 \mathrm{CPP}$ indica que no está dirigido únicamente al Ministerio Público, sino a todos los intervinientes, la regla sólo debe ser aplicable en la medida que tenga por objeto limitar el ejercicio del ius puniendi. Esto es común en el derecho comparado, siendo excepcionalísima la prohibición a particulares. En el proceso penal alemán Roxin indica que las prohibiciones "sólo están dirigidas a los órganos de persecución penal" y que "una excepción debe regir únicamente para casos de extrema violación de derechos humanos, p. ej., cuando un particular obtiene una confesión a través de tormentos insoportables" 65 .

La respuesta por la prueba producida a favor del reo no es, por ello, tan clara. Como ha señalado Isabel Echeverría "la defensa, a priori, no cuenta con una disposición constitucional que permita vulnerar derechos fundamentales en la búsqueda del elemento probatorio de descargo equiparable a la que sí existe a favor de los órganos de la persecución penal"66, y sus medios de investigación, por regla general, también son más limitados. Además "el derecho a la prueba de la inocencia debe prevalecer por sobre el interés que inspira la regla de exclusión, toda vez que al Estado no podría interesarle la condena de un inocente, entre otras consideraciones, porque ello implicaría la impunidad del verdadero culpable" ${ }^{67}$. El profesor TAvolari explica claramente el fundamento:

"Tampoco debe sorprender esta suerte de "desigualdad" institucional que se produce en favor del imputado, en el sentido que, en su beneficio, es admisible la prueba ilícita, y no lo es en su perjuicio, porque se trata de una constante de la regulación procesal penal, que consagra la igualdad de armas en función de equiparar el peso del Estado con el del particular, pero que no vacila en coadyuvar a la obtención de tal equilibrio, generando mecanismos de exclusiva utilidad del imputado, como acontece, por ejemplo, con el derecho al recurso al tribunal superior que los pactos internacionales otorgan sólo al condenado y no al acusador; con el derecho a la

\footnotetext{
63 Ibid, p. 171.

64 Lo que ha causado particulares catastróficos en materia de contratos. Ver: JANA LinETZKY, Andrés, op. cit. p. 69.

65 Roxin, Claus, op. cit. (n.14), p. 206.

66 Echeverría, Isabel, op. cit., p. 127. Una investigación penal puede afectar en modo sustancial los derechos del imputado, sea por medio de medidas precautorias personales, por otras medidas restrictivas de derechos o en último término por una sentencia condenatoria que lo prive de libertad. Piénsese además en todos los poderes de investigación de la Fiscalía, que tiene a su cargo recursos, a las policías y a distintos especialistas.

67 TAvolari, Raúl. Instituciones en el Nuevo Proceso Penal. Santiago, Chile: Editorial Jurídica de Chile, 2005, p. 157.
} 
última palabra, que se establece sólo en favor del acusado en los juicios orales o, por último, con la acción de revisión de la sentencia ejecutoriada penal dictada con fraude"68 (el destacado es nuestro).

No se nos escapa que el CPP ha consagrado el ejercicio de la acción penal no sólo para el Estado, sino también para actores como el querellante particular quien podría eventualmente vulnerar derechos fundamentales. Sin embargo, según la argumentación de la desigualdad el querellante particular -que es otra persona natural- podría en principio verse limitado a medios de investigación similares a los de la defensa y se podría pensar que él sí podría verse autorizado a vulnerar derechos fundamentales; para algunos autores, esta conclusión debe ser rechazada categóricamente ${ }^{69}$.

Con todo, Echeverría reconoce algunas excepciones relativas a vulneración como forma defensiva durante la comisión del ilícito ${ }^{70}$, basado en que previo y durante la comisión del ilícito que permite la acción penal no se ha adquirido el carácter de querellante, y así "donde aún no existe este ánimo persecutor en el particular y por tanto" -a juicio de esta autora- "es prueba que debe de ser aceptada, sin perjuicio de las sanciones pecuniarias que puedan proceder" 71 .

(III.II) LTF, CT y PCPC: Desafiante resulta una primera aproximación a cómo influyen los principios del derecho del trabajo o del derecho de familia en la interpretación de sus normas procesales, donde el tenor inequívocamente alude a todas las partes -tal como en el 276 $\mathrm{CPP}-\mathrm{y}$ no existirían sujetos exentos de esta prohibición ${ }^{72}$.

Sobre el juez de familia Iván HunTer señala que la interpretación de sus poderes no obedece sólo a la adopción de exigencias técnicas propias del derecho procesal como instrumento para la solución de conflictos sociales "en la medida que obedecen a cierta configuración proveniente del derecho sustantivo"73, por ello las facultades del juez de buscar la verdad, y de conducir el proceso deben ser interpretadas en forma coherente con la función del juez de proteger ciertos intereses, en especial ante grave insatisfacción de los derechos de niños o adolescentes ${ }^{74}$, así si el juez de familia tiene que considerar entre los principios que rigen su actividad, "el in-

68 Ibid., pp. 157-158.

69 Para esto se han dado diversas razones en doctrina, en primer lugar si el Estado que busca fines de bien común no puede prevalerse de medios ilícitos que lesiones derechos fundamentales, con menor razón podría hacerlo un privado que sólo busca satisfacer su interés particular, "plasmado de ánimo de retribución y por tanto, carente de racionalidad". Así: EchEverría, Isabel, op. cit., p. 107.

70 Ibid., p. 108, siguiendo a Hernández Basualto. Esto ocurriría por ejemplo "con la grabación oculta de la entrevista con quien ofrece o exige una dádiva en los términos del cohecho con quien ha amenazado condicionalmente”.

71 Ibíd., p. 109. Con todo dependerá de la entidad de la vulneración en último término.

72 En este sentido: Ferrada, Francisco, op. cit., p. 164.

73 Hunter, Iván. "Poderes del juez civil: algunas consideraciones a propósito del juez de familia", en: Revista de Derecho (Valdivia), vol. 20, n 1, pp. 205-229. Valdivia, Chile: Facultad de Derecho, Universidad Austral de Chile, 2007, p. 213.

74 Ibid., pp. $212-213$. 
terés superior del niño, niña o adolescente" y su derecho a ser oído (art. 16 LTF). Este derecho se encuentra reconocido en la Convención sobre los Derechos del Niño de $1989^{75}$. Por lo tanto, el juez debe definir cuál es ese interés, y "lo más lógico es que cuente con facultades para determinar cuál es dicho interés en el caso"76. Así queda por definir que influencias podría tener esta regla de interés público aplicada al proceso, y en especial a la regla del art. 31 LTF.

La naturaleza del derecho procesal laboral tampoco ha estado exenta de problemas ${ }^{77}$, pues surgen dudas si las normas de procedimiento laboral son parte del derecho del trabajo o del derecho procesal ${ }^{78}$, y si el juez para su interpretación debe hacer extensivos los principios que integran esta última, y según no pocos los que opinan que el juez "junto con sentenciar debe tratar de suplir la inferioridad jurídica en que se encuentra el trabajador frente al empleador"79, lo que se justifica en la protección a la parte que tiende a ser económicamente más débil, en el caso en que dicha inferioridad exista. La aplicación del principio in dubio pro operario ¿podría ser utilizada para incorporar criterios más laxos de admisión de elementos probatorios provenientes de trabajadores? Queda pendiente la duda y su respuesta será tanto más interesante considerando lo estricto de la norma, y que de hecho hay buenos argumentos para pensar que el art. 493 CT protege más a los empleadores, toda vez que el lugar de trabajo esta -normalmente- bajo el control del empleador, por lo que no es improbable que al conseguir ciertas pruebas el trabajador cometa algún ilícito - cuya entidad no importa- y se vea privado de prueba sólo por desconocimiento ${ }^{80}$.

Ahora bien, pese a que en estas reflexiones no podemos ofrecer una respuesta concluyente, prima facie, estamos de acuerdo con los autores de que existe algún grado de influencia entre los principios de las ramas del derecho a la regulación procesal sectorial, y que, por ejemplo, no será la misma protección la que el magistrado deberá dispensar hacia el menor en un juicio comercial (toda vez que de acuerdo a las disposiciones del art. 10 del Código de Comercio puede administrar su peculio), como si será relevante esta condición en el derecho de familia, o en caso del menor trabajador.

Son estos debates que hay que considerar, y de los que desde luego será difícil investigar atendido a que la fase de exclusión probatoria es la audiencia preliminar, y a diferencia de lo

\footnotetext{
75 Artículo 3. 1. "En todas las medidas concernientes a los niños que tomen las instituciones públicas o privadas de bienestar social, los tribunales, las autoridades administrativas o los órganos legislativos, una consideración primordial a que se atenderá será el interés superior del niño".

76 Hunter, Iván, op. cit., p. 214.

77 Walter, Rodolfo y Lanata, Gabriela, op. cit., pp. 5-6.

78 En doctrina comparada se ha afirmado que el derecho procesal del trabajo no sería clasificable dentro de categorías clásicas, sino que constituiría el llamado derecho procesal social (Fix-Zamudio, Héctor y Ovalle Favela, José. Derecho Procesal. México: Instituto de Investigaciones Jurídicas, UNAM, 1991, p. 8).

79 Walter, Rodolfo y Lanata, Gabriela, op. cit., p. 9.

80 El desmedro de sus facultades probatorias llevó a que se introdujeran, entre otras normas, el art. 493 CT.
} 
ocurrido en materia penal, no hemos visto juicios orales donde los magistrados intenten excluir pruebas, por lo que no hay registro de las razones aportadas para excluir o no pruebas determinadas.

(IV) El cuestionable debilitamiento de la prueba ilícita en materia penal

(IV.I) CPP: La mayor amplitud de las reglas de ilicitud depende de la ponderación de determinados principios que deben siempre propender a la vigencia de los derechos y las libertades ciudadanas, pues el proceso penal constituye el barómetro de las libertades ciudadanas en una sociedad. Sin embargo, en el contexto del combate a la delincuencia -o de amenazas como el terrorismo- se han introducido progresivas reglas tendientes a limitar la exclusión probatoria, que para muchos constituyen "tendencias deformantes del procedimiento penal (...) que amplían las facultades de injerencia estatal a niveles que poco tiempo atrás no hubieren sido imaginables" ${ }^{2}$. Caso paradigmático de esta tendencia es laLey 20.253, más conocida como Agenda Corta Antidelincuencia, que limita las hipótesis de exclusión probatoria a partir de actuaciones declaradas nulas ${ }^{82}$. Previo a ley, toda prueba que se originara producto de una detención ilegal podía declararse inutilizable y, de esta forma, la nulidad de la detención impedía a los fiscales hacer uso de esta prueba por ser mal habida. Hoy en cambio, la declaración de la nulidad no impide ni la formalización, ni que puedan decretarse medidas cautelares sobre esa persona, fundadas en prueba obtenida mediante actuar ilegal de las policías. Modificaciones de este tipo no son aisladas, sino que constituyen reformas legislativas que lentamente configuran una "contrarreforma" 83 .

(IV.II) LTF, CT y PCPC: ¿Es posible conciliar que mientras se le entrega "carta blanca el Ministerio Público" se establezcan estrictas prohibiciones probatorias entre particulares? $\mathrm{Pa}$ rece complejo que el legislador que consagró fuertes restricciones a la prueba entre particulares pasando a llevar garantías de defensa, a su vez entregue progresivas facultades a las policías y al Ministerio Público, permitiéndoles obtener evidencia de detenciones ilegales, aumentando la prisión preventiva, entre otras.

Pienso que muchos podrán contestarnos que el problema sistemático es la reducción de las garantías en materia penal, y no las prohibiciones en materia laboral, de familia o civil. Sin embargo, por mucho que -al menos en principio- tenga mayor potencial lesivo la vulneración que se da en materia penal, y que pueda parecer reprochable su parentesco con políticas conser-

81 Guariglia, Fabricio. "Las prohibiciones de valoración probatoria en el procedimiento penal", en: Jueces para la Democracia, $\mathrm{n}^{\circ}$ 26, pp. 76-80. Madrid, España: Asociación Jueces para la Democracia, 1996, p. 80.

82 En lo relativo a este punto ley señala que "La declaración de ilegalidad de la detención no producirá efecto de cosa juzgada en relación con las solicitudes de exclusión de prueba que se hagan oportunamente, de conformidad con lo previsto en el artículo 276 ”.

83 En ese sentido: Hernández Basualto, Héctor. La detención declarada ilegal y sus consecuencias sobre las medidas cautelares y el régimen de exclusión de prueba. En: Seminario "Agenda Corta Antidelincuencia” (noviembre 2008, Valparaíso, Chile). Santiago, Chile: Centro de Documentación de la Defensoría Penal Pública, 2010, p. 25. 
vadoras del tipo "Law and Order"; el hecho de que la crisis de coherencia del sistema de prueba ilícita civil no obedezca a una opción político-legislativa tan marcada, no debe hacernos olvidar que aquí también hay derechos fundamentales en juego, y que por lo mismo ambas situaciones deben ser objeto de nuestra atención. Así, la importancia del derecho a la prueba, nos lleva a creer que también sería necesario reformar al menos el art. $453 \mathrm{~N}^{\circ} 4$ CT para adecuarlo a respetar debidamente el derecho a la defensa, y esperar que la jurisprudencia realice un análisis siempre considerando cuales son los derechos fundamentales que están en la balanza, y no sea el derecho a la prueba siempre el que deba ceder.

\section{PALABRAS FINALES}

Esperamos con estas líneas haber contribuido a pensar un poco más algunos de los problemas de la prueba ilícita y su estándar en el derecho chileno. No se trata como podría caricaturizarse, que apoyemos el descubrimiento de la verdad a cualquier precio, ni se quiera reflotar la inquisición. Se trata de una invitación a que reflexionemos sobre la coherencia interna que debe tener en lo particular el sistema procesal de exclusión probatoria y más generalmente el derecho chileno y el problema de la interpretación de los derechos fundamentales por la judicatura.

Esto no es fácil por la variedad de temas que se entrelazan aquí. El contenido de los derechos fundamentales, la pregunta por su eficacia entre particulares, el manejo y la comprensión de distintas ramas del derecho con principios muy marcados y literatura que no dialoga entre sí, son sólo algunos de los problemas. Evidentemente existen otros problemas prácticos en esta materia, como por ejemplo, el momento de la exclusión probatoria ${ }^{84}$, o las formas de impugnar sentencias obtenidas con prueba ilícita, entre otros.

Un sistema eficiente, razonable y coherente es necesario, porque al final del día contribuye a garantizar el debido proceso, la igualdad ante la ley, y permite reforzar nuestra confianza en el derecho democrático.

84 Lo que ha suscitado más discusiones en el ámbito procesal penal (Horvitz, María Inés y López, Julián, op. cit. Cfr. HernÁNDez Basualto, Héctor. La exclusión de la prueba ilícita en el nuevo proceso penal chileno. Santiago, Chile: Colección de investigaciones jurídicas Universidad Alberto Hurtado, 2005). Pese a la mala técnica legislativa del art. $453 \mathrm{~N}^{\circ} 4 \mathrm{CT}$-que da la idea de no valoración- se ha impuesto la idea de que la audiencia preliminar debe ser el momento idóneo pues se trata de exclusión probatoria por la regulación sistemática de las normas sobre prueba en el nuevo proceso laboral (FerRADA, Francisco, op. cit. p. 172) la doctrina mayoritaria y la jurisprudencia lo han entendido así, Cfr. Orellana, Fernando. Comentarios al nuevo proceso laboral. Santiago, Chile: Librotecnia, 2009, p. 188. Esta interpretación se debe al tenor literal de la norma, pero el autor reconoce que sería una mejor alternativa la exclusión a la no valoración. 


\section{REFERENCIAS BIBLIOGRÁFICAS}

\section{ARTí́CUlOS Y OBRAS}

Aldunate, Eduardo. Derechos Fundamentales. Santiago, Chile: Legal Publishing, 2008.

Armenta Deu, Teresa. La prueba ilícita (Un estudio comparado). Madrid, España: Marcial Pons, 2009.

Atria, Fernando. “Ubi Ius, Ibi Remedium? La Relevancia Jurídica de los Derechos Humanos”, en: Revista de Estudios de la Justicia, $n^{\circ} 12$, pp. 35-47. Santiago, Chile: Centro de Estudios de la Justicia, Facultad de Derecho, Universidad de Chile, 2003.

Cabezas Pino, René. Aspectos relevantes de la prueba en el nuevo proceso laboral. Tesis (Para optar al grado de licenciado en Ciencias Jurídicas y Sociales). Santiago, Chile: Universidad de Chile, Facultad de Derecho, 2010.

Carocca, Alex. La garantía constitucional de la defensa procesal. Barcelona, España: J. M. Bosch Editor, 1998.

CArocca, Alex. "Una primera aproximación al Tema de la Prueba Ilícita en Chile", en: Ius et Praxis, vol. 4, n 2, pp. 301-322. Talca, Chile: Facultad de Derecho, Universidad de Talca, 1998.

Cea Egaña, José Luis. Derecho constitucional chileno. Santiago, Chile: Ediciones de la Universidad Católica de Chile, 2008.

Echeverría, Isabel. Los derechos Fundamentales y la Prueba Ilícita. Con especial referencia a la prueba ilícita aportada por el querellante particular y por la defensa. Tesis (Para optar al grado de licenciado en Ciencias Jurídicas y Sociales). Santiago, Chile: Universidad de Chile, Facultad de Derecho, 2007.

Ferrada, Francisco. La prueba ilícita en sede civil. Tesis (Para optar al grado de Magíster en Derecho) Santiago, Chile: Universidad de Chile, Facultad de Derecho, 2009.

Ferrer Beltrán, Jordi. "Derecho a la prueba y racionalidad de las decisiones judiciales”, en: Jueces para la Democracia, n 47, pp. 27-34. Madrid, España: Asociación Jueces para la Democracia, 2003.

Fix-Zamudio, Héctor y Ovalle Favela, José. Derecho Procesal. México: Instituto de Investigaciones Jurídicas, UNAM, 1991.

Gonzales García, Jesús María. “El Proceso Penal Español y La Prueba Ilícita”, en: Revista de Derecho (Valdivia), vol. 18, n² 2, pp. 187-211. Valdivia, Chile: Facultad de Derecho, Universidad Austral de Chile, 2005.

Gozaíni, Osvaldo. Obtención y Valoración de la Prueba Ilícita. En: De la Oliva Santos, Andrés, Palomo Vélez, Diego (coords.). Proceso Civil. Hacia una nueva justicia civil. Santiago, Chile: Editorial Jurídica de Chile, 2007.

GUARIGLIA, Fabricio. "Las prohibiciones de valoración probatoria en el procedimiento penal", en: Jueces para la Democracia, n²6, pp. 76-80. Madrid, España: Asociación Jueces para la Democracia, 1996.

Hernández Basuatto, Héctor. La exclusión de la prueba ilícita en el nuevo proceso penal chileno. Santiago, Chile: Colección de investigaciones jurídicas Universidad Alberto Hurtado, 2005.

Hernández Basualto, Héctor. La detención declarada ilegal y sus consecuencias sobre las medidas cautelares y el régimen de exclusión de prueba. En: Seminario "Agenda Corta Antidelincuencia" (noviembre 2008, Valparaíso, Chile). Santiago, Chile: Centro de Documentación de la Defensoría Penal Pública, 2010.

Horvitz, María Inés y López, Julián. Derecho Procesal Penal Chileno. Tomo II. Santiago, Chile: Editorial Jurídica de Chile, 2004.

Hunter, Iván. "Poderes del juez civil: algunas consideraciones a propósito del juez de familia", en: Revista de Derecho (Valdivia), vol. 20, n 1, pp. 205-229. Valdivia, Chile: Facultad de Derecho, Universidad Austral de Chile, 2007.

Jana Linetzky, Andrés, La eficacia horizontal de los derechos fundamentales. En: VV.AA., Los derechos fundamentales. Seminario Latinoamérica de Teoría Constitucional 2001. Buenos Aires, Argentina: Editores del Puerto, 2003. 
Jara Bustos, Francisco. "La facilidad probatoria en el procedimiento de tutela laboral. Constitucionalidad y tramitación procesal", en: Revista Chilena de Derecho del Trabajo y de la Seguridad Social, vol. 1, n 2, pp. 153-184. Santiago, Chile: Departamento de Derecho del Trabajo y de la Seguridad Social, Facultad de Derecho, Universidad de Chile, 2010.

Jequier, Eduardo. "La obtención ilícita de la fuente de la prueba en el proceso civil. Análisis comparativo del ordenamiento jurídico español y chileno”, en: Revista Chilena de Derecho, vol. 34, n³ 3, pp. 457-494. Santiago, Chile: Facultad de Derecho, Universidad Católica de Chile, 2007.

Larroucau Torres, Jorge. La prueba en el proceso civil. Tesis (Para optar al grado de Doctor en Derecho) Santiago, Chile: Universidad de Chile, Facultad de Derecho, 2010.

Marinoni, Luiz Guilherme, Pérez Ragone, Álvaro, Núñez Ojeda, Raúl. Fundamentos del Proceso Civil. Hacia una teoría de la adjudicación. Santiago, Chile: Abeledo Perrot - Legal Publishing, 2010.

Maturana, Cristián. Aspectos Generales de la Prueba. Apuntes de Derecho Procesal II. Santiago, Chile: Departamento de Derecho Procesal, Facultad de Derecho, Universidad de Chile, 2006.

Melis Valencia, Christian. Los derechos fundamentales de los trabajadores como limites a los poderes empresariales. Santiago, Chile: Abeledo Perrot - Legal Publishing, 2009.

Midón, Marcelo. Pruebas Ilícitas. Análisis Doctrinario y Jurisprudencial. Mendoza, Argentina: Ediciones Jurídicas de Cuyo, 2002.

Miranda Estrampes, Manuel. El concepto de prueba ilícita y su tratamiento en el proceso penal. Barcelona, España: J. M. Bosch Editor, 2004.

Núñez Ojeda, Raúl. El Ofendido por el Delito y la Prueba en el Enjuiciamiento Criminal Español. En: Coloma, Rodrigo (ed.). La Prueba en el Nuevo Proceso Penal Oral. Santiago, Chile: Lexis-Nexis, 2002.

Orellana, Fernando. Comentarios al nuevo proceso laboral. Santiago, Chile: Librotecnia, 2009.

Picó i Junoy, Joan. El derecho a la prueba en el proceso civil. Barcelona, España: J.M. Bosch Editor, 1996.

Picó I Junoy, Joan. La prueba ilícita y su control judicial en el proceso civil. En: III Congreso Panameño de Derecho Procesal (16, 17, 18 y 19 de agosto de 2006, Ciudad de Panamá, Panamá). Ciudad de Panamá, Panamá: Instituto Colombo Panameño de Derecho Procesal, 2006.

Piedrabuena Richard, Guillermo. Orienta a los fiscales en el tema de exclusión de la prueba ilícita. <En línea> Oficio del Ministerio Público N 167. Santiago, abril 2002 [Citado 20 enero 2011] Disponible en World Wide Web: <www.ministeriopublico.cl.>

Roxin, Claus. "La protección de la persona en el derecho procesal penal alemán”. En su: La Evolución de la Politica Criminal, el Derecho Penal y el Proceso Penal. Valencia, España: Tirant lo Blanch, 2000.

Roxin, Claus. Derecho procesal penal-2a edición- Buenos Aires, Argentina: Editores del Puerto, 2003.

Taruffo, Michele. "Investigación Judicial y Producción de Prueba por las Partes”, en: Revista de Derecho (Valdivia), vol. 15, n 2, pp. 205-213. Valdivia, Chile: Facultad de Derecho, Universidad Austral de Chile, 2003.

TARuffo, Michele. La prueba. Madrid, España: Marcial Pons, 2008.

Tavolari, Raúl. Instituciones en el Nuevo Proceso Penal. Santiago, Chile: Editorial Jurídica de Chile, 2005.

Walter, Rodolfo y Lanata, Gabriela. Régimen legal del nuevo proceso laboral chileno -6a edición-Santiago, Chile: Legal Publishing, 2009.

Zalaquett, José y Nash Claudio. "Proceso Penal y Derechos Humanos", en: Revista de Derecho Procesal, vol. 20, pp. 61-97. Santiago, Chile: Departamento de Derecho Procesal, Facultad de Derecho, Universidad de Chile, 2005.

Zapata, María Francisca. La Prueba Ilícita. Santiago, Chile: Lexis-Nexis, 2004. 
DERECHO Y HUMANIDADES, $\mathrm{N}^{\circ} 19$, 2012, pp. 273-296

Francisco Jara Bustos /¿Eficacia horizontal de los derechos fundamentales? el problema del estándar de la prueba ilícita en el dercho Chileno

\section{Documentos}

Anteproyecto de Código Procesal Civil (APCP) elaborado por la Universidad de Chile. Disponible en $<$ www.minjusticia.gob.cl>

Bases Fundamentales para la Reforma de la Justicia Laboral y Previsional. Disponible en <www.cejamericas.org>.

Historia de la Ley No 19.968. Biblioteca del Congreso Nacional. 30 de Agosto de 2004. Disponible en <www.bcn.cl>.

Historia de la Ley No 20.087. Biblioteca del Congreso Nacional. 03 de Enero de 2006. Disponible en <www.bcn.cl>.

Historia de la Ley No 20.260. Biblioteca del Congreso Nacional. 29 de Marzo de 2008. Disponible en <www.bcn.cl>.

Proyecto de Código Procesal Civil (PCPC) presentado a tramitación Mensaje No 398-357 de 2009. Disponible en $<$ www.minjusticia.gob.cl> 